Int. J. Dev. Biol. 59: 235-240 (2015)

doi: $10.1387 / \mathrm{ijdb} .140275 \mathrm{ma}$

\title{
Comparative expression analysis of pfdn6a and tcp1 $\alpha$ during Xenopus development
}

\author{
SILVIA MARRACCI ${ }^{1}$, DAVIDE MARTINI",1, MARTINA GIANNACCINI",1,2, GUIDO GIUDETTI"\#,1, LUCIANA DENTE \\ and MASSIMILIANO ANDREAZZOLI*,1 \\ ${ }^{1}$ Unità di Biologia Cellulare e dello Sviluppo, Dipartimento di Biologia, Università di Pisa and \\ 2Istituto di Scienze della Vita, Scuola Superiore Sant'Anna, Pisa, Italy
}

\begin{abstract}
We recently identified pfdn6a and tcp1 $\alpha$ (also known as cct- $\alpha$ ) as genes coregulated by the transcription factor $\mathrm{Rx} 1$. The proteins encoded by these genes belong to two interacting complexes (Prefoldin and "chaperonin containing t-complex polypeptide 1"), which promote the folding of actin and tubulin and have more recently been reported to be involved in a variety of additional functions including cell cycle control and transcription regulation. However, little is known about the expression and function of these two genes during vertebrate development. To assess whether pfdn6a and tcp $1 \alpha$ display a general coordinated expression during Xenopus development, we determined, by RT-PCR and in situ hybridization, the spatio-temporal expression pattern of pfnd6a, which was not previously described, and compared it to that of tcp1 $\alpha$, extending the analysis to stages not previously investigated for this gene. We detected maternal transcripts of pfnd6a in the animal hemisphere at early blastula stage. During gastrulation, pfdn6a was expressed in the involuting mesoderm and subsequently in the anterior and dorsal neural plate. At tailbud and tadpole stages, pfdn6a RNA was mainly detected in the forebrain, midbrain, eye vesicle, otic vesicle, branchial arches, and developing pronephros. The pfnd6a expression pattern largely overlaps with that of $t c p 1 \alpha$ indicating a spatio-temporal transcriptional coregulation of these genes in the majority of their expression sites, which is suggestive of a possible involvement in the same developmental events.
\end{abstract}

KEY WORDS: pfdn6, hke2, tcp1, cct, Xenopus embryogenesis

Molecules linking and coordinating cytoskeletal dynamics and gene expression are of particular interest as they play crucial roles in many aspects of a cell's life. A growing number of proteins appears to belong to this class and a recent example is represented by Prefoldin (PFDN), a cochaperone that cooperates with the chaperonin TCP1 (also known as CCT, chaperonin containing tailless complex polypeptide 1), which was shown to operate both in the cytoplasm and in the nucleus (Millan-Zambrano and Chavez, 2014). The function originally described for eukaryotic PFDN, a heterohexameric complex assembled from six different subunits (two different $\alpha$ and four different $\beta$ subunits), is to promote the folding of actin and tubulin through the interaction with TCP1, a complex assembled from two stacked rings, each composed of eight different but related subunits (CCT $\alpha, \beta, \gamma, \delta, \varepsilon, \zeta, \eta, \theta$ in mammals and CCT1-8 in yeast) (Hansen et al., 1999; Martín-Benito et al., 2002). However, a large body of evidence has recently indicated that PFDN and TCP1 carry out additional functions including control of cell cycle, protein degradation and transcription, as well as exerting protective effects against the accumulation of aggregated proteins, such as pathogenic huntingtin and amyloid- $\beta$ (Pejanovic et al., 2012; Millan-Zambrano and Chavez, 2014).

Functional experiments have shown a central role played by PFDN and TCP1 also during metazoan development. In Caenorhabditis elegans, RNAi screens indicate that knockdown of individual PFDN or TCP1 subunits causes morphological abnormalities and variably penetrant embryonic lethal phenotypes, suggesting that these proteins are required for multiple tissue development and embryonic viability (Sönnichsen et al., 2005). In Drosophila, mutations in the PFDN3 homologue mgr cause reduced tubulin synthesis in somatic and germinal cells, leading to mitotic and

Abbreviations used in this paper: PFDN, prefoldin.

\footnotetext{
*Address correspondence to: Massimiliano Andreazzoli. Unità di Biologia Cellulare e dello Sviluppo, SS12 Abetone e Brennero, 56127 Pisa, Italy. Tel. +39-050-2211485. Fax + 39-050-2211495 E-mail: massimiliano.andreazzoli@unipi.it

\#Note: These authors equally contributed to this work.

\#Present address: Scuola Superiore Sant'Anna, The BioRobotics Institute, Translational Neural Engineering Group. 56025 Pontedera (Pisa), Italy.
}

Accepted: 5 March 2015.

ISSN: Online 1696-3547, Print 0214-6282 
meiotic defects and resulting in morphological abnormalities and developmental lethality (Delgehyr et al., 2012). In addition, it is reported that the TCP1 complex is involved in cleavage furrow formation in Drosophila early embryos (Monzo et al., 2010). The role of PFDN and TCP1 was also investigated in a few animal models of vertebrate development. PFDN1-deficient mice develop defective cytoskeletal function, loss of nerve bundles, hydrocephaly, neuromuscular defects, abnormal lymphocyte development and function, and a shortened life span (Lee et al., 2011). Moreover, genetic disruption in the murine Pfdn5 gene, leads to a reduction in formation of microtubules and microfilaments, resulting in progressive neurodegeneration, hydrocephalus and reproductive abnormalities, indicating that PFDN5 is required for normal sensory and neuronal development (Lee et al., 2011). In zebrafish, a mutation in the $\gamma$ subunit of TCP-1 was found to be responsible for the mutant no tectal neuron (ntn), which is characterized by defects in retinal ganglion cells differentiation and tectal neuropil formation, small pectoral fins and underdeveloped jaw skeletons (Matsuda and Mishina, 2004). In mouse, tcp1 $\alpha$ is observed at the morula and blastocyst stages and its expression is higher in post implantation embryos than in any adult organs except testis, indicating that $t c p 1 \alpha$ expression is regulated spatially and temporally during embryogenesis (Kubota et al., 1992). Finally, suppression of TCP1 activity in mouse photoreceptors leads to malformation of the outer segments and triggers retinal degeneration, indicating an essential role of TCP1 in the differentiation and survival of this photosensitive cell type (Sinha et al., 2014).

Despite the pivotal role of amphibian models in understanding

A

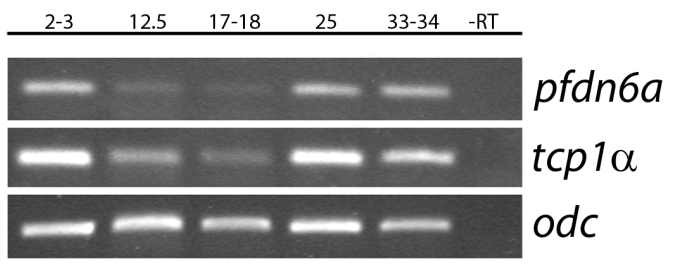

B

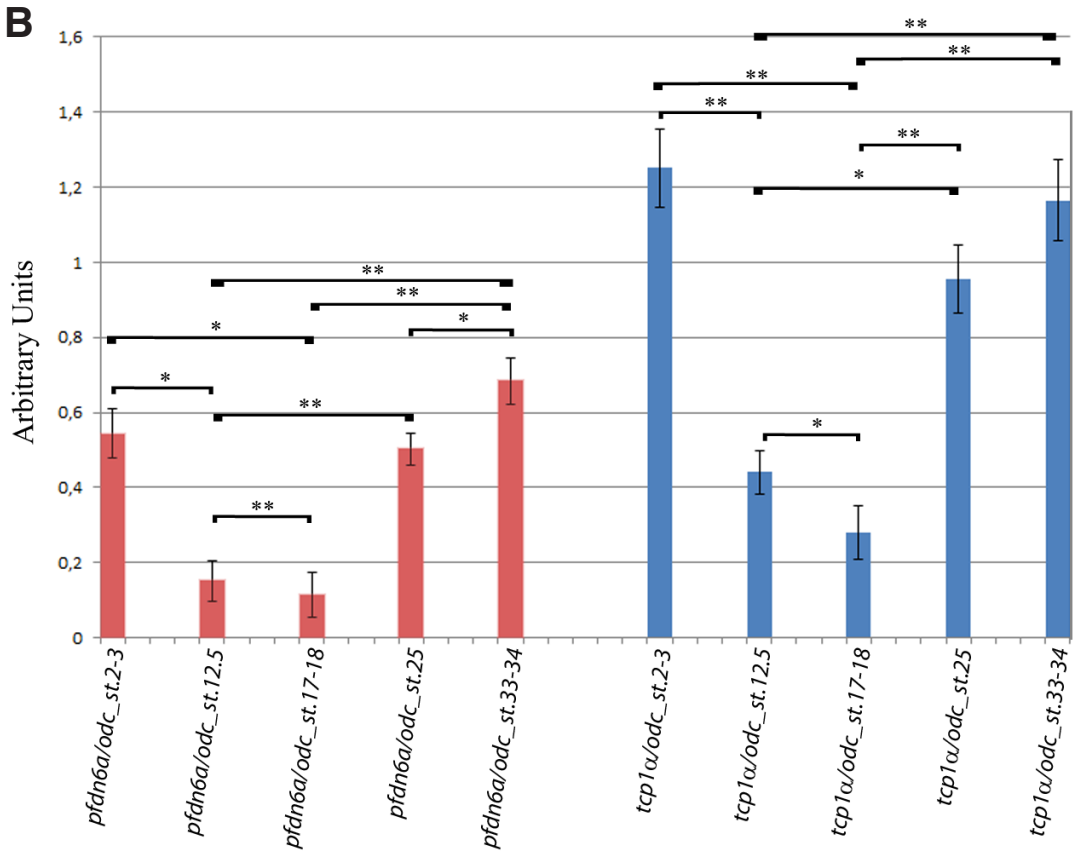

vertebrate development, there are no data available about PFDN and little is known about TCP1 in these animal systems. To date, the only data reported on the amphibian homologue of TCP1 concern the expression of tcp $1 \alpha(\mathrm{CCT} \alpha)$ in the axolotl (Ambystoma mexicanum), in which it is spatially and temporally regulated during neural and somitic development (Sun et al., 1995), and the expression in Xenopus laevis embryos of tcp $1 \alpha$ and $t c p 1 \gamma$, which appear to be developmentally regulated in neural-derived and myogenic lineages (Dunn and Mercola, 1996). Recently, we selected pfdn6a and $t c p 1 \alpha$ in the course of a screen aimed at identifying genes coherently controlled by the retinal key regulator Rx1 (Giannaccini et al., 2013; Giudetti et al., 2014), consistently with previous data indicating a role of PFDN and TCP1 in retinal development (Matsuda and Mishina 2004; Lee et al., 2011 Sinha et al., 2014). The coregulation of these two genes by $\mathrm{Rx} 1$ suggested that they could display a general coordinated expression during embryogenesis. This prompted us to determine the spatio-temporal expression pattern of pfnd6a, which was not previously described, and compare it to the expression of $t c p 1 \alpha$, extending the analysis to stages that, for the latter gene, had not being previously investigated.

\section{Results and Discussion}

To provide novel insights into the regulation of pfdn6a we determined its spatio-temporal expression pattern during Xenopus development. Moreover, we performed a comparative analysis of pfdn6aand tcp $1 \alpha$ expression to evaluate the possible coregulation of these two genes.

\section{Temporal expression of pfdn6a and tcp1 $\alpha$ during Xenopus development}

To analyze the temporal expression pattern of pfdn6a and compare it to that of tcp $1 \alpha$ during embryonic development, we performed RT-PCR assays on cDNAs obtained from Xenopus embryos at different developmental stages.

The two genes display both maternal and zygotic expression, being detected before and after the midblastula transition (stage 8; Newport and Kirschner, 1982). They show a similar temporal expression profile, with their transcripts decreasing from the early blastomere stage to stage 18 and then increasing gradually from stage 25 to stage 33-34 (Fig. 1 A,B).

tcp $1 \alpha$ temporal expression pattern is consistent with that of the axolotl homologue, displaying maternal transcripts, detected in fertilized eggs, which are subsequently down-regulated in early gastrulae.

Fig. 1. RT-PCR analysis of pfdn6a and tcp $1 \alpha$ expression during Xenopus development. (A) pfdna6 and tcp $1 \alpha$ expression during embryonic development. cDNA derived from Xenopus laevis embryos at different stages (indicated at the top of the panel) was amplified using primers specific for pfdn6a, tcp $1 \alpha$ and ornithine decarboxylase gene (odc). The cDNAs were normalized to odc. For control reactions, reverse transcriptase was omitted (-RT). (B) Histogram representing the optical integrated density ratios of pfdn6a, tcp $1 \alpha$ and odc RT-PCR bands. The optical density was calculated using the ImageJ software. Values are means of 3 independent experiments. Significance: $p$-value $<0.05$ : *; $p$-value<0.01: **. 


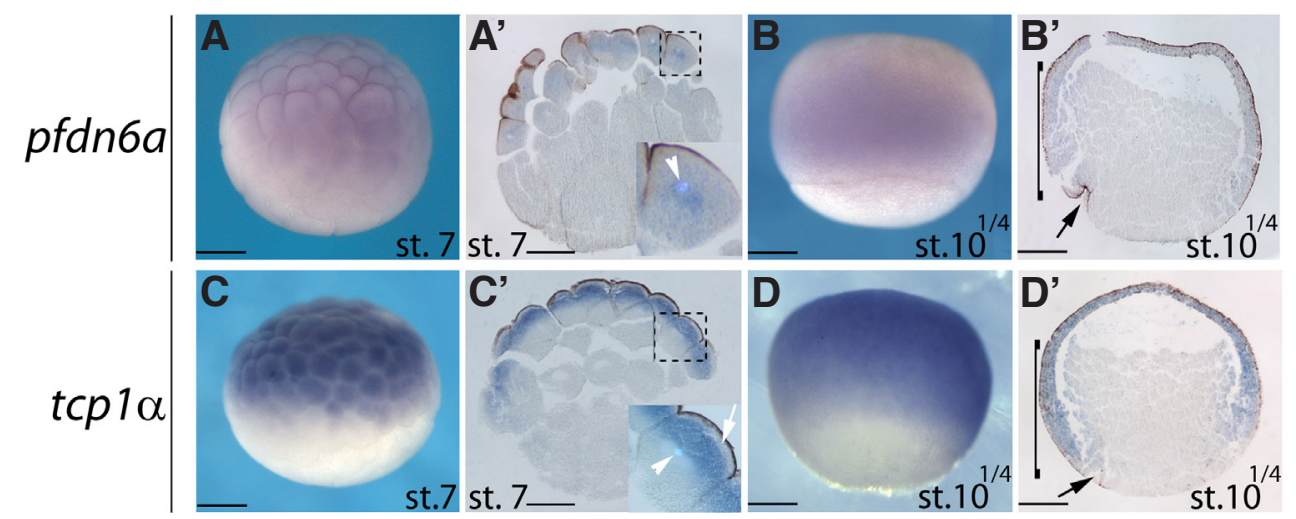

Fig. 2. Whole mount in situ hybridization analysis of pfdn6a and tcp 1 $\alpha$ during segmentation and gastrulation. Stages of embryos are indicated at the bottom right corner of each panel. (st.: stage), while the analyzed gene is indicated to the left of each row. $(\mathbf{A}, \mathbf{C})$ Lateral views of stage 7 embryos; animal pole to the top, vegetal pole to the bottom. ( $\left.\mathbf{A}^{\prime}, \mathbf{C}^{\prime}\right)$ Sagittal sections of the hybridized embryos shown in (A) and $(C)$, respectively; the insets in $\left(A^{\prime}, C^{\prime}\right)$, indicated by the dashed line square in each panel, show the intracellular localization of the two transcripts in animal blastomeres: the white arrow in $\left(C^{\prime}\right)$ shows absence of the tcp $1 \alpha$ transcript in subcortical portion of cytoplasm; white arrowheads in ( $A^{\prime}$, $\left.C^{\prime}\right)$ indicate Hoechst-stained nuclei. (B,D) Lateral view of stage 101/4 embryos; animal pole to the top, vegetal pole to the bottom. (B', D') Sagittal sections of the hybridized embryos shown in $(B)$ and $(D)$, respectively; black arrows point to the blastopore lip, square brackets indicate the involuting mesoderm. Scale bars, 250 um.

Similarly, zygotic transcripts are mainly expressed in mid-neurula and later stage embryos (Sun et al., 1995). On the other hand, in mouse, tcp1 is expressed in post-implantation embryos and the amount of its mRNA decreases during development (from 7.5 to 17.5 day dpc) (Kubota et al., 1992). Differences between amphibians and mouse in early tcp 1 expression may be ascribed to the possible lack of a maternal transcript in the mouse embryo, which is known to depend much less than amphibians on maternal RNAs stored in the oocyte. In addition, high levels of tcp 1 expression have been previously correlated with rapidly growing cells, which need to efficiently fold abundant proteins required for active growth (Kubota et al., 1992). As the rate of early embryonic cell divisions is remarkably higher in amphibian than in mammals, this aspect may contribute to the observed expression differences.

Differently from $\operatorname{tcp} 1 \alpha$, the developmental expression of pfdn6a in Vertebrates has not been previously described.

\section{Spatial expression pattern of pfdn6a and tcp1 $\alpha$ during Xeno- pus development}

Maternal transcripts of both genes are detected in the animal hemisphere during blastula stage (st.7) (Fig. 2 A,A',C,C'), with a different intracellular localization pattern: pfdn6a transcripts are mainly located in the perinuclear region (Fig. 2A', inset), while tcp $1 \alpha$ is expressed in the apical portion of animal blastomeres except for the cytoplasmic subcortical region (Fig. 2C', inset). At early gastrula stage (st. $10^{1 / 4}$ ) pfdn6a and tcp $1 \alpha$ are both expressed in the ectoderm and in the presumptive mesoderm of the marginal zone (Fig. 2 B, B', D, D'). In particular, while sagittal sections of the hybridized embryos show a clear expression of tcp $1 \alpha$ in the involuting mesoderm (Fig. 2 D,D'square bracket), pfdn6a appears to share a similar expression pattern although with a significantly lower hybridization signal (Fig. 2 B,B' square bracket).

Partially similar expression is observed in the axolotl where tcp $1 \alpha$ transcript has been found localized along the blastopore at mid-gastrula stage (Sun et al., 1995).

At neurula stages (st.13-19) pfdn6a and tcp $1 \alpha$ are expressed in anterior and dorsal regions of the neural plate (Fig. $3 A, B, C, F, G$, $H)$. The presence of transcripts of both genes in migrating neural crests is visible in stage 16 and stage 19 embryos (Fig. 3 B,C,G,H white arrowheads). As expected from our previous microarray data (Giudetti et al., 2014), we observed that Rx1 overexpression leads to the repression of both pfdn6a and tcp $1 \alpha$ at stage 18/19 (Fig. 3D, I). As Xenopus development proceeds (st.22-23) the two genes are broadly expressed in the head, including eye anlagen and neural crests, as well as in dorsal and posterior region of the trunk (Fig. $3 \mathrm{E}, \mathrm{J}$ ). As the expression of $t c p 1 \alpha$, (alias CCTa) between stage 23 and 42 was previously reported (Dunn and Mercola, 1996) for these stages we mainly describe the expression of pfdn6a, except for those cases where a comparison with tcp $1 \alpha$ is relevant.

In stage 27 embryos, a specific pfdn6a hybridization signal is

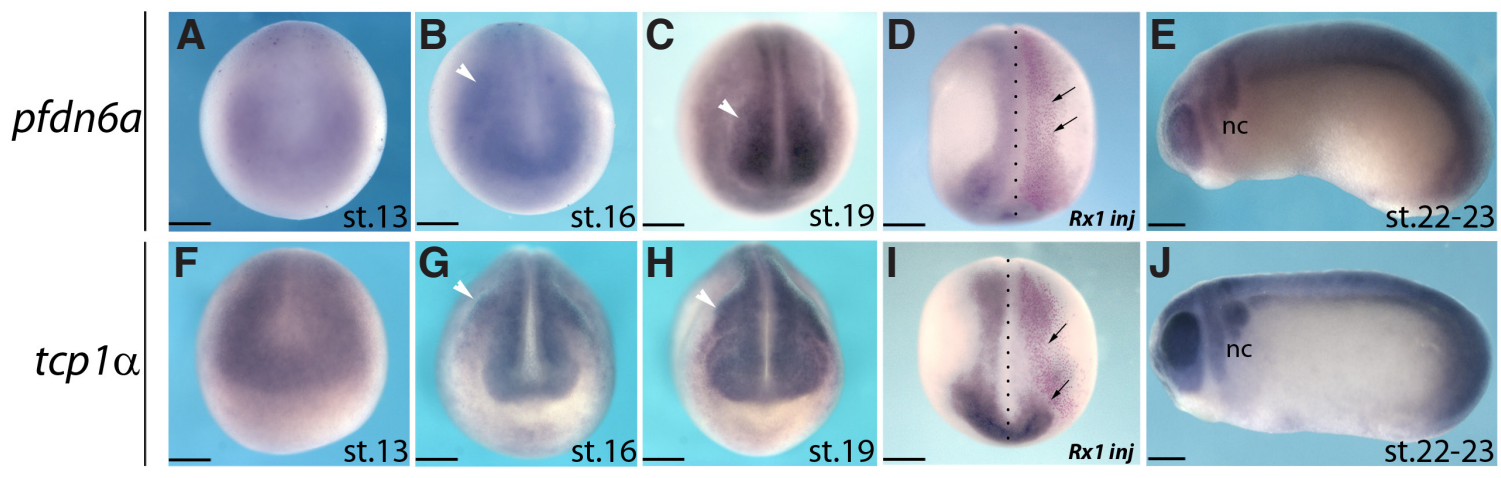

Fig. 3. Whole mount in situ hybridization analysis of pfdn6a and tcp1 $\alpha$ during neurulation. (A-C, F-H) Frontal views (dorsal to the top) of hybridized embryos at the indicated neurula stages; white arrowheads indicate neural crests. (D, I) Dorsal view of stage 18/19 embryos injected unilaterally with Rx1 RNA and nuclear LacZ RNA as a tracer (red staining). Arrows point at regions displaying stronger repression. (E, J) Lateral views of hybridized stage 22-23 embryos; anterior is to the left; nc: neural crests. Scale bars, 250 um. 


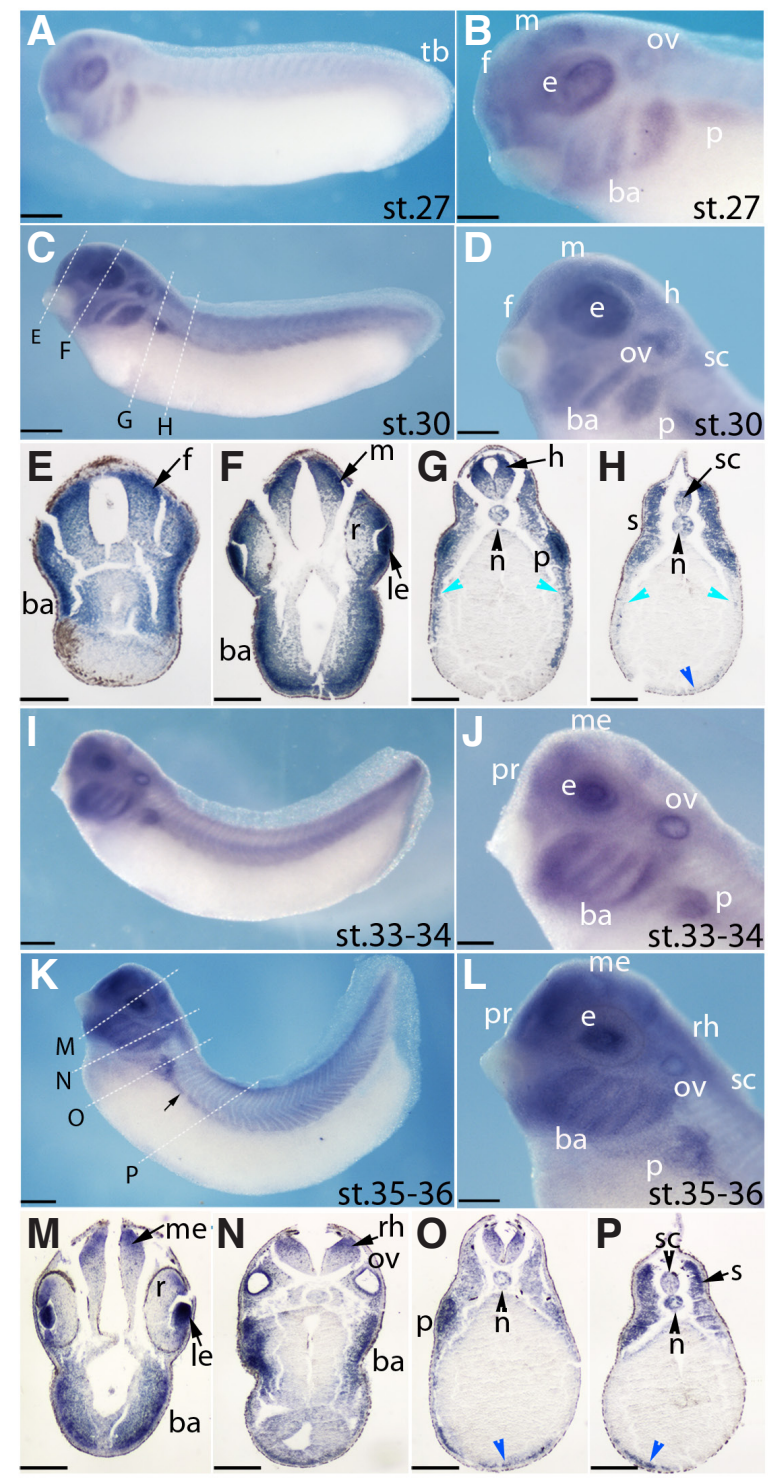

evident in forebrain, midbrain, eye vesicle, otic vesicle, branchial arches, anterior region of developing pronephros (Fig. $4 \mathrm{~A}, \mathrm{~B}$ ). Somites show a pfdn6a signal progressively increasing towards tailbud region (Fig. 4A). In stage 30 embryos, pfdn6a extends its expression pattern to other regions of central nervous system such as hindbrain and spinal cord (Fig. 4 D, G,H). Moreover, sections of stage 30 hybridized embryos reveal that this gene is expressed in developing retina and lens anlagen (Fig. 4F), notochord (Fig. 4 $\mathrm{G}, \mathrm{H}$ ), lateral plate mesoderm (Fig. $4 \mathrm{G}, \mathrm{H}$, light blue arrowheads). Furthermore, from stage 30 to later analyzed stages (st. 35-36), pfdn6a is expressed not only in the pronephric anterior region but also in the pronephric developing duct (Fig. 4 C,D,I-L).

The pfdn6a hybridization pattern observed in stage 30 embryos persists also at stage 33-34 and 35-36 (Fig. $4 \mathrm{I}$-L). In particular, sections of stage 35-36 embryos show higher levels of pfdn6a hybridization signal in dorsal region of mesencephalon and rhomboencephalon (Fig. $4 \mathrm{M}, \mathrm{N}$ ), retinal region and lens anlagen (Fig. $4 \mathrm{M}$ ), brachial arches (Fig. $4 \mathrm{M}, \mathrm{N}$ ), otic vesicle (Fig. $4 \mathrm{~N}$ ), pronephros (Fig. 4O), notochord (Fig. 4 O,P) and spinal cord (Fig. 4P). From stage 30 to stage $35-36$ pfdn6a is expressed in a ventral region of the embryos (Fig. $4 \mathrm{H}, \mathrm{O}, \mathrm{P}$, blue arrowheads).

As described by Dunn and Mercola (1996), we observed that Xenopus tcp $1 \alpha$ is mainly expressed in neurogenic-derived, including developing cranial neural crest cells, and myogenic lineages

Fig. 4 (left). Whole mount in situ hybridization analysis of pfdn6a expression in tadpole embryos. Stages of embryos are indicated at the bottom right corner of each panel. (B, $\mathbf{D}, \mathbf{J}, \mathbf{L})$ Magnified views of $(\mathbf{A}, \mathbf{C}, \mathbf{I}, \mathbf{K})$, respectively. In panels (A-D, I-L) anterior is to the left. Dashed lines in (C) point to the planes of the sections shown in (E-H). Dashed lines in (K) indicate the planes of the sections shown in (M-P). Light blue arrowheads in $\mathbf{( G , H ) ~ p o i n t ~ o u t ~ a ~ h y b r i d i z a t i o n ~ s i g n a l ~ i n ~ l a t e r a l ~ p l a t e ~ m e s o d e r m ~ a t ~ s t a g e ~}$ 30. Blue arrowheads point to pfdn6a-expressing ventral regions of stage 30 (H) and stage 35-36 embryos (O,P). Black arrow in (K) indicates pronephric developing duct. ba: brachial arches; e: eye; f: forebrain; h: hindbrain; le: lens; m: midbrain; me: mesencephalon; n: notochord; ov: otic vesicle; $p$ : pronephros; pr:prosencephalon; rh: rhomboencephalon; r: retina; s: somite; sc: spinal cord; tb: tailbud. Scale bars in (A, C, I, K), $500 \mu \mathrm{m}$; in (B, D, J, L), $250 \mu \mathrm{m}$; in (E-H, M-P), $200 \mu \mathrm{m}$.
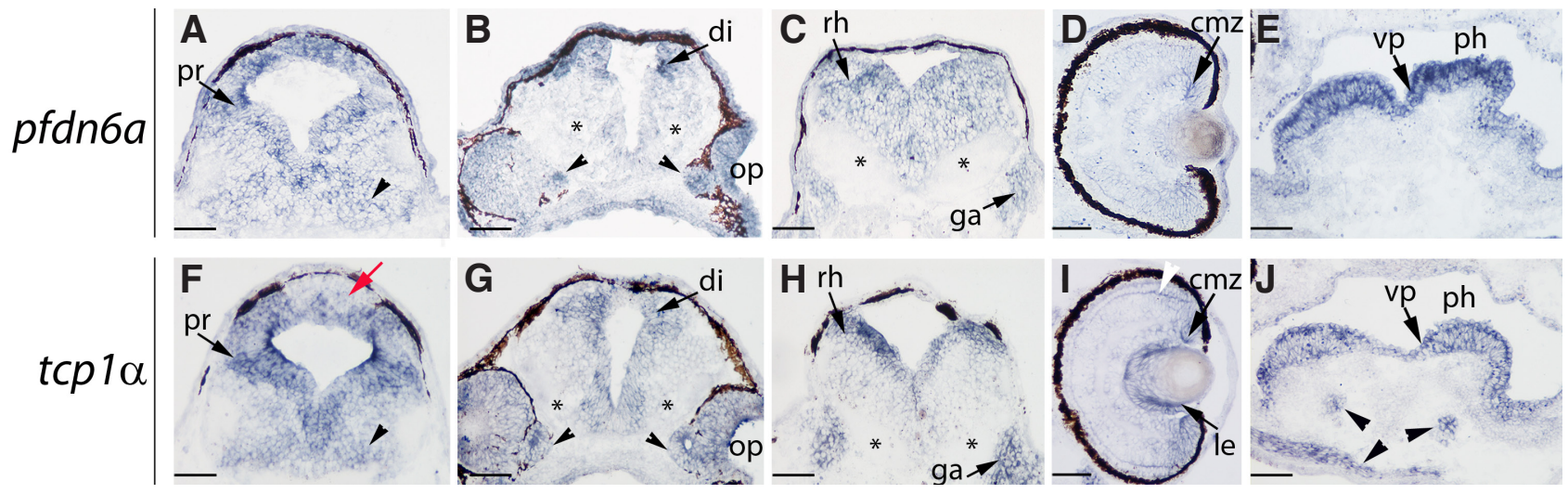

Fig. 5. Cryosections of stage 42 embryos hybridized with pfdn6a (A-E) and tcp 1 $\alpha$ probes (F-J). The red arrow in (F) denotes absence of tcp1 $\alpha$ signal in a dorsal region of prosencephalon. Black arrowheads in $(\mathbf{A}, \mathbf{F})$ indicate a region located above the pharynx, labeled with pfdn6a and tcp1 $\alpha$, respectively. The asterisks in $\mathbf{( B , C , G , H ) ~ i n d i c a t e ~ w h i t e ~ m a t t e r ~ a t ~ t h e ~ l e v e l ~ o f ~ d i e n c e p h a l o n ~} \mathbf{( B , G )}$ and rhomboencephalon $(\mathbf{C}, \mathbf{H})$. Black arrowheads in

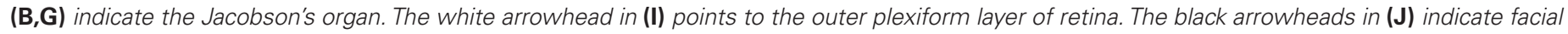
muscles. cmz: ciliary marginal zone; ga: ganglia; le: lens; op: olfactory pits; ph: pharynx; pr: prosencephalon; rh: rhomboencephalon; vp: velar plate. Scale bars in (A-C, E, F-H, J), $100 \mu \mathrm{m}$; in (D, I), $50 \mu \mathrm{m}$. 
(data not shown). In axolotl, the highest expression of tcp $1 \alpha$ was detected in developing neural tissue, brain and somites in stage 16 (midneurula) until stage 43 (hatching) embryos (Sun et al., 1995).

In parallel, a detailed comparison of the expression patterns of pfdn6a and tcp $1 \alpha$ in anterior regions was performed on stage 42 embryos (Fig. 5). Hybridized cryostat sections show that both genes are expressed in prosencephalon, mesencephalon, rhomboencephalon and cranial ganglia (Fig. 5 A-C,F-H), although tcp $1 \alpha$ is not expressed in dorsal prosencephalic regions (Fig. 5F, red arrow). Conversely, the two genes are not expressed in white matter of diencephalon and rhomboencephalon (Fig. $5 \mathrm{~B}, \mathrm{C}, \mathrm{G}, \mathrm{H}$, asterisks). In the eye, tcp $1 \alpha$ is expressed in ciliary marginal zone $(\mathrm{CMZ})$, outer plexiform layer (white arrowhead) and in cells of the proliferative layer of lens (Fig. 5I), while pfdn6a displays mainly a weak expression in the CMZ (Fig. 5D). Furthermore, both pfdn6a and tcp $1 \alpha$ transcripts are detected in olfactory pits and Jacobson's organ (also known as vomeronasal organ) (Fig. 5B, G, black arrowheads), which both constitute the larval olfactory organ of Xenopus (Hansen et al., 1998). Finally, the transcripts of both genes have been detected in head regions located between prosencephalon and pharynx (Fig. 5A, F, black arrowheads), and in velar plate of the mouth located in ventral oral endoderm (Fig. 5 E,J). However, we observed that pfdn6a transcripts are not found in some facial muscles underlying the pharynx that express tcp $1 \alpha$ (Fig. $5 \mathrm{E}, \mathrm{J}$; Dunn and Mercola, 1996)

In conclusion, we found that both pfdn6a and tcp $1 \alpha$ are spatially and temporally regulated during embryogenesis of Xenopus. Moreover, their transcripts show many sites of coexpression in embryos at different developmental stages, suggesting that both genes share a common transcriptional regulation and could be involved in the same developmental events.

\section{Materials and Methods}

\section{RNA extraction and RT-PCR analysis}

Total RNA was extracted from different embryonic stages by using Mini RNA Isolation Kit (Nucleospin RNA XS, Macherey Nagel). First strand cDNA was synthesized using Superscript II Reverse Transcriptase (Invitrogen), from $1 \mu \mathrm{g}$ of total RNA. RT-PCR analysis was performed using gene-specific sets of primers:

tcp $1 \alpha$-forward: 5'-AGTCTGTCGTACCCGGAGGT-3'

tcp $1 \alpha$-reverse: 5'-AGCATTCACCGCTAGGGTTT-3'

pfdn6a-forward-: 5'-CCGAGATTGCCAAATACCAG-3'

pfdn6a-reverse: 5'-ACTGAGCCTCAAGCTTTTGC-3'

odc-forward: 5'-GGGCTGGATCGTATCGTAGA-3'

odc-reverse: 5'-CTTCAGGGAGAATGCCATGT-3'

\section{In situ hybridization and microinjections}

Xenopus embryos were staged according to Nieuwkoop and Faber (1967).

Whole-mount in situ hybridization was performed according to standard protocols (Harland et al., 1991) with minor modifications (see Marracci et al., 2013). Probes for pfdn6a and tcp $1 \alpha$ were transcribed from cDNA clones AGENCOURT_11041475 (GenBank Acc. no. CA988538.1) and XL418a19ex (GenBank Acc. no. BP674881), respectively.

Antisense transcripts were prepared by plasmid linearization with Sall (pfdn6a) or BamHI (tcp1 $\alpha$ ) and in vitro transcription using T7 and T3 RNA polymerase (Roche), respectively. Sense transcripts were used as negative control (data not shown).

For in situ hybridization on cryostat sections (12 $\mu \mathrm{m})$, embryos were fixed and cryoprotected following the experimental procedure previously described (D'Autilia et al., 2010; Marracci et al., 2011).
$\mathrm{Rx} 1$ and nuclear-LacZ were microinjected in one dorsal blastomere at four-cell stage, as previously described (Giudetti et al., 2014).

\section{Paraffin sectioning}

Whole-mount hybridized embryos were paraffin-embedded and cut at a thickness of 15-29 $\mu \mathrm{m}$ with a Reichert-Jung Autocut 2040 Microtome. After Hoechst-counterstaining, the sections were washed and mounted in Aqua Poly/Mount (Polysciences Inc.)

\section{Acknowledgements}

We are grateful to Naoto Ueno, forgenerously providing the XL418a19ex plasmid, and thank Marzia Fabbri, Donatella De Matienzo and Elena Landi for technical assistance, and Salvatore Di Maria for frog care.

\section{References}

D'AUTILIA S, BROCCOLI V, BARSACCHI G, ANDREAZZOLI M (2010). Xenopus Bsx links daily cell cycle rhythms and pineal photoreceptor fate. Proc Natl Acad Sci USA 107: 6352-6357.

DELGEHYR N, WIELAND U, RANGONE H, PINSON X, MAO G, DZHINDZHEV NS, MCLEAN D, RIPARBELLI MG, LLAMAZARES S, CALLAINI G, GONZALEZ C, GLOVER DM (2012). Drosophila Mgr, a Prefoldin subunit cooperating with von Hippel Lindau to regulate tubulin stability. Proc NatIAcad SciU SA 109:5729-5734.

DUNN M, MERCOLA M (1996). Cloning and Expression of Xenopus CCTgamma, a Chaperonin Subunit Developmentally Regulated in Neural-Derived and Myogenic Lineages Dev Dyn 205: 387-394.

GIANNACCINI M, GIUDETTI G, BIASCI D, MARIOTTI S, MARTINI D, BARSACCHI G, ANDREAZZOLI M (2013). Rx1 defines retinal precursor identity by repressing alternative fates through the activation of TLE2 and Hes4. Stem Cells31:2842-2847.

GIUDETTI G, GIANNACCINI M, BIASCI D, MARIOTTI S, DEGL'INNOCENTI A, PERROTTA M, BARSACCHI G, ANDREAZZOLI M (2014). Characterization of the $\mathrm{R} \times 1$-dependent transcriptome during early retinal development. Dev Dyn 243: 1352-1361.

HANSEN W J, COWAN N J, WELCH W J (1999). Prefoldin-nascent chain complexes in the folding of cytoskeletal proteins. J Cell Biol 145: 265-77.

HARLAND R M (1991). In situ hybridization: an improved whole-mount method for Xenopus embryos. Methods Cell Biol 36: 685-95.

KUBOTA H, WILLISON K, ASHWORTH A, NOZAKI M, MIYAMOTO H, YAMAMOTO H, MATSUSHIRO A, MORITA T (1992). Structure and expression of the gene encoding mouse t-complex polypeptide (Tcp-1). Gene 120:207-215.

LEE Y, SMITH R S, JORDAN W, KING B L, WON J, VALPUESTA J M, NAGGERT J $\mathrm{K}, \mathrm{NISHINA} P \mathrm{M}$ (2011). Prefoldin 5 is required for normal sensory and neuronal development in a murine model. J Biol Chem 286: 726-736

MARRACCI S, MICHELOTTI V, CASOLA C, GIACOMA C, RAGGHIANTI M (2011) Daz-and Pumilio-like genes are asymmetrically localized in Pelophylax (Rana) oocytes and are expressed during early spermatogenesis. J Exp Zool (Mol Dev Evol) 316:330-338.

MARRACCI S, GIANNINI M, VITIELLO M, ANDREAZZOLI M, DENTE L (2013). Kidins220/ARMS is dynamically expressed during Xenopus laevis development Int J Dev Biol 57: 787-792.

MARTÍN-BENITO J, BOSKOVIC J, GÓMEZ-PUERTAS P, CARRASCOSA J L, SIMONS C T, LEWIS S A, BARTOLINI F, COWAN N J, VALPUESTA J M (2002). Structure of eukaryotic prefoldin and of its complexes with unfolded actin and the cytosolic chaperonin CCT. EMBO J 21:6377-6386.

MATSUDA N, MISHINA M. (2004). Identification of chaperonin CCT gamma subunit as a determinant of retinotectal development by whole-genome subtraction cloning from zebrafish no tectal neuron mutant. Development 131:1913-1925.

MILLÁN-ZAMBRANO G, CHÁVEZ S (2014). Nuclear functions of prefoldin. Open Biol 4. pii: 140085. doi: 10.1098/rsob.140085.

MONZO K, DOWD S R, MINDEN J S, SISSON J C (2010). Proteomic analysis reveals CCT is a target of Fragile $\mathrm{X}$ mental retardation protein regulation in Drosophila. Dev Biol 340:408-418.

NEWPORT J, KIRSCHNER M (1982). A major developmental transition in early Xenopus embryos: II. Control of the onset of transcription. Cell 30: 687-696.

NIEUWKOOP P D, FABER J (1967). Normal Table of Xenopus laevis. Amsterdam, 
The Netherlands: North Holland Publishing Company.

PEJANOVIC N, HOCHRAINER K, LIU T, AERNE B L, SOARES M P, ANRATHER $\mathrm{J}$ (2012). Regulation of nuclear factor KB (NF-KB) transcriptional activity via p65 acetylation by the chaperonin containing TCP1 (CCT). PLoS One 7:e42020.

SINHA S, BELCASTRO M, DATTA P, SEO S, SOKOLOV M (2014). Essential role of the chaperonin CCT in rod outer segment biogenesis. Invest Ophthalmol Vis Sci 55: 3775-3785.
SÖNNICHSEN B, KOSKI L B, WALSH A, MARSCHALL P, NEUMANN B, BREHM M, ALLEAUME A M, ARTELT J, BETTENCOURT P, CASSIN E, et al. (2005). Full-genome RNAi profiling of early embryogenesis in Caenorhabditis elegans. Nature 434: 462-469.

SUN H B, NEFF A W, MESCHER A L, MALACINSKI G M (1995). Expression of the axolotl homologue of mouse chaperonin t-complex protein-1 during early development. Biochim Biophys Acta 1260:157-166.

\section{Further Related Reading, published previously in the Int. J. Dev. Biol.}

Kidins220/ARMS is dynamically expressed during Xenopus laevis development

Silvia Marracci, Marianna Giannini, Marianna Vitiello, Massimiliano Andreazzoli and Luciana Dente

Int. J. Dev. Biol. (2013) 57: 787-792

http://dx.doi.org/10.1387/ijdb.130080sm

Dicer inactivation causes heterochronic retinogenesis in Xenopus laevis

Sarah Decembrini, Massimiliano Andreazzoli, Giuseppina Barsacchi and Federico Cremisi Int. J. Dev. Biol. (2008) 52: 1099-1103

http://dx.doi.org/10.1387/ijdb.082646sd

The Xenopus ortholog of the nuclear hormone receptor Nr2e3 is primarily expressed in developing photoreceptors

Reyna I. Martinez-De Luna and Heithem M. El-Hodiri

Int. J. Dev. Biol. (2007) 51: 235-240

http://dx.doi.org/10.1387/ijdb.062236rm

Retinal stem cells in vertebrates: parallels and divergences

Marcos A. Amato, Emilie Arnault and Muriel Perron

Int. J. Dev. Biol. (2004) 48: 993-1001

http://dx.doi.org/10.1387/ijdb.041879ma

Regulation of vertebrate eye development by $R x$ genes

Travis J. Bailey, Heithem El-Hodiri, Li Zhang, Rina Shah, Peter H. Mathers and Milan Jamrich Int. J. Dev. Biol. (2004) 48: 761-770

http://dx.doi.org/10.1387/ijdb.041878tb

5 yr ISI Impact Factor $(2013)=2.879$

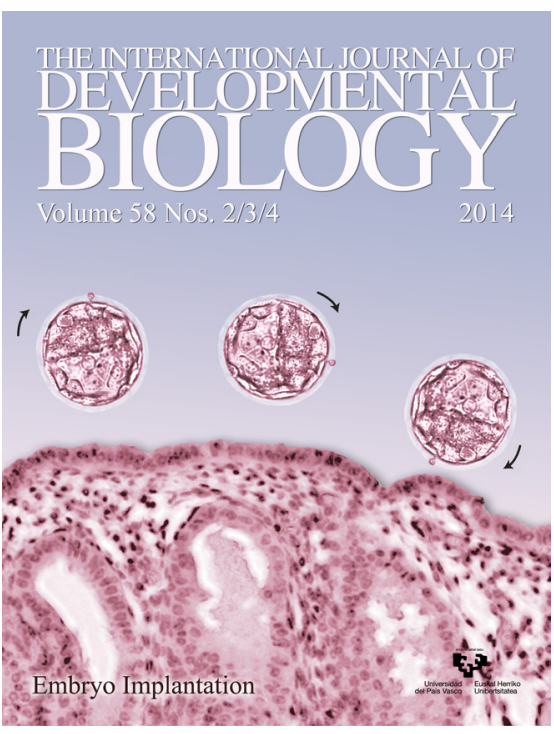

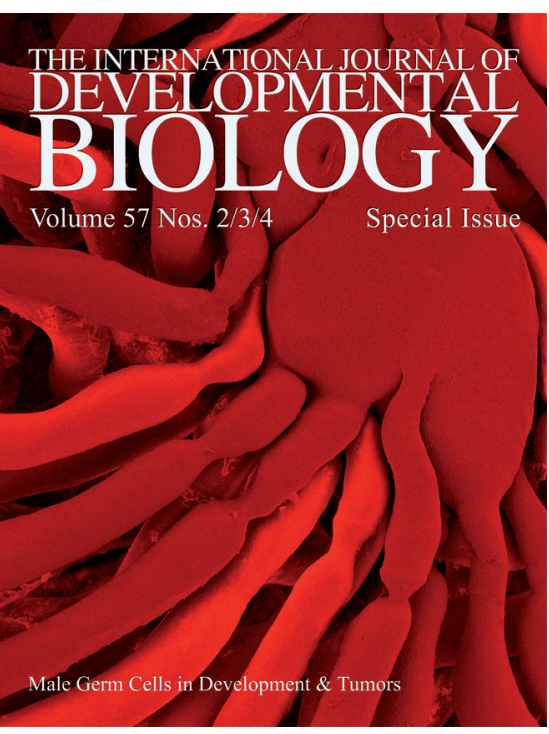

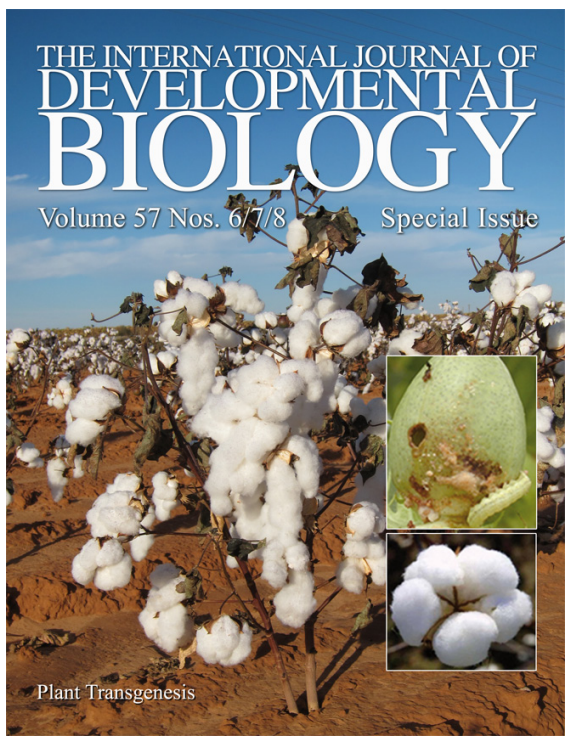

